\title{
Perception and Anxiety of Indian Population during COVID-19 Pandemic: A Questionnaire-based Survey
}

\author{
Malarkodi Senniyappan ${ }^{1, *}$, Xavier Belsiyal Chellappan', Rupinder Deol', Chandrakala Sankarapandian ${ }^{2}$
}

\begin{abstract}
Background: The rapid and widespread of the COVID-19 virulent disease has become an important cause of concern among the general public. The declaration of the pandemic has led to a massive public reaction. The perception, anxiety of the general public will perhaps have a major bearing on the course of the coronavirus disease pandemic. Aim: This study aims to assess the perception and anxiety of the Indian population regarding the COVID-19 pandemic. Methods: A cross-sectional web-based survey was conducted through an online platform (Google form) among the Indian population. A structured questionnaire was prepared to collect data and it took about 6 min to complete the questionnaire, and a total of 351 responses were received. Descriptive (frequency, percentage, mean, standard deviation) and inferential (Spearman's rho correlation coefficient) statistics were used to analyze the collected data. Results: Out of 351 responders, 192 (54.7\%) were female, 198 (56.4\%) were aged between 18-29 years, most of them were living in cities, $178(50.7 \%)$, and 239, (68.1\%) were graduates and above. Most of the responders $179(51.0 \%)$ were used social media to obtain information regarding COVID-19. More than half of the Indian residents viewed this coronavirus pandemic negatively (58\%) and half of them $(51.3 \%$ ) were had a mild level of anxiety; nearly $29 \%$ had a moderate level of anxiety, few were under (19.9\%) severe level anxiety. Conclusion: There is a necessity to exaggerate the understanding and address the mental health issues of people during this COVID-19 pandemic. Key words: Perception, Anxiety, General Public, Covid-19, Pandemic.
\end{abstract}

\section{Malarkodi $\mathrm{S}^{1, *}$, Xavier Belsiyal C' ${ }^{1}$, Rupinder Deol ${ }^{1}$, Chandrakala Sankarapandian ${ }^{2}$ ${ }^{1}$ College of Nursing AllMS, Rishikesh, Uttarakhand, INDIA. \\ ${ }^{2}$ Princess Nourah Bint Abdulrahman University, Riyadh, KINGDOM OF SAUDI ARABIA (KSA).}

\section{Correspondence}

\section{Mrs. Malarkodi S}

Assistant Professor, College of Nursing AlIMS, Rishikesh-243201, Uttarakhand, INDIA.

Mobile no: +91-7533800333

Email: malar.nur@aiimsrishikesh.edu.in

History

- Submission Date: 24-11-2020;

- Revised Date: 09-01-2021;

- Accepted Date: 13-03-2021;

DOI : 10.5530/ijmedph.2021.2.16

\section{Article Available online}

http://www.ijmedph.org/v11/i2

\section{Copyright}

(c) 2021 Phcog.Net. This is an openaccess article distributed under the terms of the Creative Commons Attribution 4.0 International license.

\section{INTRODUCTION}

COVID 19 pandemic is sweeping across humanity beyond oceans and borders. COVID-19 disease originated in Wuhan City, Hubei Province of China, in December 2019. ${ }^{1}$ At that time, enormous occurrences have been reported in further Chinese Provinces and many nearby countries to spread in countries in due course. ${ }^{1}$ Thus, the World Health Organization (WHO) stated this outbreak as a global pandemic on 12, Mar 2020, with an incessant increase in reported cases. ${ }^{2}$

India is a developing country, and the present generation did not expose to such a massive pandemic ever. In India, the first COVID-19 infected case was reported on Jan 30, 2020. Since then, more cases have been reported, with 878, 254 diseased people, 553,470 recoveries (including one migration), and 23,174 deaths in the country till now as of Jul 13,2020. Since the few new reported cases, firm measures have been imposed by the MoHFW to regulate the transmission of the virus, comprising restrictive outdoor activities, suspending schools, reducing social contacts, and prohibiting religious gatherings. It has resulted in an environment of fear and anxiety among the general public. $^{2}$

Santabárbara et al. 2020 et al. did a meta-analysis, shows the projected overall prevalence of anxiety of
$25 \%$, which diverse significantly across the various tools used to assess anxiety. Constantly stated risk factors for anxiety involved initial or peak phase of the outbreak, female, younger age, marital, social isolation, unemployment, and student status, financial hardship, low educational level, lack of knowledge of COVID-19, epidemiological or clinical risk of disease, and certain lifestyle and personality variables. $^{3}$

The country has announced several phases of lockdown. This incidence has created a massive public effect in all aspects like economically, personally, socially, and psychology for people leading to heightened levels of anxiety. Recent studies have shown dissimilar levels of distress and anxiety among the public contrarily exposed to the COVID 19 pandemic. The lifestyle revolution and jeopardy of being infected may cause anxiety disorders. ${ }^{4} \mathrm{~A}$ meta-analysis done by Santabárbara et al. 2021 suggests that healthcare workers are undergoing substantial levels of anxiety during the COVID-19 pandemic, particularly those on the frontline and nurses. Nevertheless, worldwide longitudinal studies are needed to completely apprehend the effect of the pandemic on healthcare workers' mental health. ${ }^{5}$

Cite this article : Malarkodi S, Belsiyal XC, Deol R, Sankarapandian C. Perception and Anxiety of Indian Population during COVID-19 Pandemic: A Questionnaire-based Survey. Int J Med Public Health. 2021;11(2):90-5. 
Chen, F et al. did a study among adolescents which revealed that female adolescents had a higher risk of developing depression and anxiety throughout the pandemic. The late adolescents were more anxious than younger ones. ${ }^{4}$ Inspiring the public to adopt such behaviors can be challenging. Studies of how people reacted to the outbreak of severe acute respiratory syndrome in 2002 propose that perceptions or beliefs about an explosion may be vital in determining compliance with formal advice. Literature portrays human behaviors as influenced by people's understanding and opinion to decide whether to adopt prudent practices in response to an outbreak. The act of the general public will probably have a significant bearing on the course of the coronavirus disease 2019 pandemic.

Exploring their perceptions and anxiety may aid health care professionals to plan strategies to educate the general public. Considering the seriousness of the COVID 19 pandemic, researchers felt an urgent need to assess the perception and anxiety of the Indian population regarding the COVID 19 pandemic.

To assess perceptions and anxiety concerning COVID 19 pandemic, researchers carried out a cross-sectional online survey from a representative sample of the population of India. This survey provided a snapshot of the perception, and public concerns resulting in anxiety at the start of the coronavirus outburst, during a period of scientific ambiguity about the risks posed by the virus.

\section{METHODS}

\section{Survey Instrument and Dissemination}

A cross-sectional web-based survey was carried out using a survey instrument to obtain responses from the general population of India during the second week of Apr 9-Jun 21, 2020. The survey comprised of 16 items structured questionnaire of perception and general anxiety regarding COVID 19. A Google online survey form was developed with a consent form attached to it. 23 experts were listed up from the field of nursing, community health, psychiatric from that the seven randomly-selected experts were selected to read the questionnaire to assess the readability. Then the pilot web survey was conducted among 12 randomly (list of the population from Rishikesh and selected through simple lottery method) selected general populations to determine clarity, relevance, and acceptability. These participants were excluded from the main research. Modifications were made in the questions as required to organize and facilitate better comprehension before the final survey.

Researchers were collected data from residents of various states of India by using the Snowball sampling technique. The link to the questionnaire was sent through e-mails, WhatsApp, and other social media to the contacts of the responders from the different geographic areas of India. Thus, the link was sent to individuals apart from the first point of contact and so on. Since it was an online survey, participants with access to the internet only could take part. Responder age who were more than 18 years, able to understand English, and willing to give informed consent were included. On receiving and clicking the link, the participants got auto-directed to the survey information and informed consent. After they agreed, the questionnaire starts with the details of socio-demographic variables and so on.

\section{Content of the survey instrument and scoring system}

The survey tool comprised 16 closed-ended questions and took just about 6 min to complete. The 16 items survey divided into three sections and section one contained socio-demographic variables like age, gender, state, district, habitat, education, occupation, family monthly income, religion, history of quarantine, etc. In section two, nine questions concerning perception on a 5 -point Likert scale, and there were seven items scale in section three regarding generalized anxiety among the public during the lockdown period of the pandemic of the novel coronavirus.

The perception of the general population towards the COVID-19 pandemic was assessed using 5 points Likert scales (9 items) and rated from strongly agree to strongly disagree (1-5 points). The scale had both positive and negative questions, which were scored accordingly. The responder's perception was categorized as positive $(\geq 23)$ and negative $(\leq 24)$.

Anxiety was assessed using the generalized anxiety disorders (GAD-7) scale. ${ }^{6}$ It is a standardized 4 points scale rating from not at all sure (0) several days (1) over half the days (2) nearly every day (3) and anxiety was classified as mild $(0-6)$, moderate $(7-11)$, severe anxiety $(<11)$ respectively.

\section{Data analysis}

The received data were coded and entered in Microsoft excel sheet and analyzed using Statistical Package for the Social Sciences version 20.0. Descriptive statistics were used in the study to calculate frequencies, mean, standard deviation, and proportions were used to estimate the results of the study. The spearman rho correlation test was applied to examine the level of the relationship among variables. A $p$-value $<.05$ was considered statistically significant.

\section{Ethical considerations}

Permission was obtained from the Institutional Ethics Committee (AIIMS/IEC/2020/268) of All India Institute of Medical Sciences, Rishikesh. Participation in this survey was voluntary and was not compensated. Online informed written consent was obtained from the responder before commencing the study. The responders were allowed to refuse or withdraw their consent at any stage of the survey and promised anonymity and confidentiality of data.

\section{RESULTS}

An online (Google) survey was conducted to assess perception and generalized anxiety among the Indian population during COVID 19 pandemic. A total of 351 participants were responded, in that all were above 18 years of age and Indian origin. The study included only those responders who understood English and had access to the internet. Therefore, by default, all individuals with a higher level of education were included, the lowest educational level in this study was observed to be standard $8^{\text {th }}$, and the highest qualification of the population was graduation and above (60\%). Nearly $43.3 \%$ of the population were healthcare professionals. The mean age of the responder was $36.2 \pm 6.36$ years, $54.7 \%$ were females, and $41.3 \%$ were males, the remaining did not prefer to mention their gender. More than $50 \%$ of respondents were from urban areas, the majority of the respondents $68 \%$ were Hindus, $13.96 \%$ were Sikh, and $11.96 \%$ belonged to the Muslim community. Most of the participants were not either experience quarantine and looked after COVID-19 affected person (Table 1). The respondents were from 27 states and union territories of the country with maximum representation from Tamil Nadu, Punjab, followed by Uttarakhand, Gujarat, Himachal Pradesh, and Haryana (Figure 1).

Perception towards COVID-19 pandemic: More than half of the Indian residents perceived this coronavirus pandemic negatively (58\%) remaining $42 \%$ view this positively (Figure 2 ). As shown in Table 2, more than $48 \%$ of the participants agreed to the outbreak of coronavirus 2019 has created a worldwide health emergency. The majority of responders (76.9\%) thought that social distancing will prevent virus spread. Approximate $(43 \%)$ of the responders were uncertain about the public are not following social distancing seriously. However, $51.8 \%$ of them considered effective health education/mass media 
Table 1: Responders characteristics.

\begin{tabular}{|c|c|}
\hline \multicolumn{2}{|l|}{$\mathrm{N}=351$} \\
\hline Profile & $\mathrm{n}(\%)$ \\
\hline \multicolumn{2}{|l|}{ Age (in years) } \\
\hline 18-29Years & $198(56.4)$ \\
\hline 30-40 Years & $99(28.2)$ \\
\hline 41-50 Years & $38(10.8)$ \\
\hline$>50$ Years & $16(4.6)$ \\
\hline Mean + SD & $36.2+01.369$ \\
\hline \multicolumn{2}{|l|}{ Gender } \\
\hline Male & $145(41.3)$ \\
\hline Female & $192(54.7)$ \\
\hline Prefer not to say & $14(4.0)$ \\
\hline \multicolumn{2}{|l|}{ Habitat } \\
\hline Village & $77(22.0)$ \\
\hline Town & $96(27.3)$ \\
\hline City & $178(50.7)$ \\
\hline \multicolumn{2}{|l|}{ Educational status } \\
\hline Secondary education & $53(15.1)$ \\
\hline Higher secondary education & $59(16.8)$ \\
\hline Graduate and above & $239(68.1)$ \\
\hline \multicolumn{2}{|l|}{ Occupational Status } \\
\hline Unemployed / Homemaker & $85(24.2)$ \\
\hline Laborer & $29(8.3)$ \\
\hline Self-employed/Business & $43(12.3)$ \\
\hline Private sector & $99(28.2)$ \\
\hline Government sector & $95(27.0)$ \\
\hline \multicolumn{2}{|c|}{ Family Monthly Income (In rupees) } \\
\hline 10000 & $64(18.2)$ \\
\hline $10001-20000$ & $67(19.1)$ \\
\hline $20001-30000$ & $75(21.4)$ \\
\hline$>30001$ & $145(41.3)$ \\
\hline \multicolumn{2}{|l|}{ Religion } \\
\hline Hindu & $239(67.7)$ \\
\hline Muslim & $19(5.4)$ \\
\hline Christian & $42(12.0)$ \\
\hline Sikh & $49(14.0)$ \\
\hline Others* & $2(01.6)$ \\
\hline \multicolumn{2}{|l|}{ Health care worker } \\
\hline Yes & $152(43.3)$ \\
\hline No & $199(56.7)$ \\
\hline \multicolumn{2}{|c|}{ Role of Health care worker $(n=152)$} \\
\hline Nurse/student nurse & $72(47.4)$ \\
\hline Doctors & $36(23.7)$ \\
\hline Pharmacist & $24(15.8)$ \\
\hline Technician & $20(13.1)$ \\
\hline \multicolumn{2}{|l|}{ Source of information } \\
\hline Family/friends & $065(18.5)$ \\
\hline
\end{tabular}

$\begin{array}{lc}\text { Mass media } & 179(51.0) \\ \text { Health care workers } & 107(30.5) \\ \text { Are you in quarantine } & 79(22.5) \\ \text { Yes } & 272(77.5) \\ \text { No } & 23(06.6) \\ \text { Witnessed persons affected with coronavirus } & \text { infection? } \\ \text { Yes } & 328(93.4) \\ \text { No } & 17(4.8) \\ \text { Look after coronavirus affected or suspected persons } \\ \text { Yes } & 334(95.2) \\ \text { No } & \\ \text { Relationship of the person with you(n=17) } & 3(17.6) \\ \text { Family members } & 3(17.6) \\ \text { Relatives } & 2(11.8) \\ \text { Neighbors } & 2(11.8) \\ \text { Colleague } & 7(41.2)\end{array}$

communication adopted in India is helpful in the prevention of COVID 19. Approximately $60 \%$ of participants believed that Health care workers, police, and sanitary worker's contribution to fighting against coronavirus are well apparent.

\section{Anxiety level during COVID 19 pandemic}

Among 351 respondents, half of them (51.3\%) were having a mild level of anxiety, nearly $29 \%$ having a moderate level of anxiety, few had $19.9 \%$ ) severe level anxiety (Table 3). As shown in Table 4, near about half of the participants were feeling nervous, anxious about the COVID-19. A total of $45 \%$ agreed on not being able to stop or control worrying about the pandemic situation. More than $50 \%$ of participants felt being so restless that it's hard to sit still.

\section{Co-relation of perception and anxiety among the general public}

There was a significant positive relationship seen between perception and anxiety $(P=0.01)$. The positive perception indicates lesser anxiety, the results suggest that as the public perceives this COVID 19 pandemic, their level of anxiety decreases (Table 5).

\section{DISCUSSION}

Pandemics and epidemics are common occurrences. The COVID-19 pandemic is the most significant public health emergency of our time and the biggest threat facing us since world war-II. At these times, the general public endures numerous challenges. Lack of awareness and unconcerned mindset of the population can seriously affect the preparation to face such challenges. The consequences of such a pandemic are always severe and can adversely affect a given population's mental health. Therefore, the present research was conducted to explore the perception and anxiety of the general public on COVID-19.

Our findings revealed that the mean age of the participants was $36.2 \pm 6.36$ years, and about $54.7 \%$ were females. Most of the participants had a school education of more than eight years, and about $43.3 \%$ of them were related to the healthcare field. These findings are in concurrence with Vadivu, Annamuthu (2020), ${ }^{7}$ Al-Hanawi et al. ${ }^{8}$ Roy D, Tripathy S, Kar SK, Sharma N, Verma SK, Kaushal $V^{9}$ where studies from southeast Asia, 


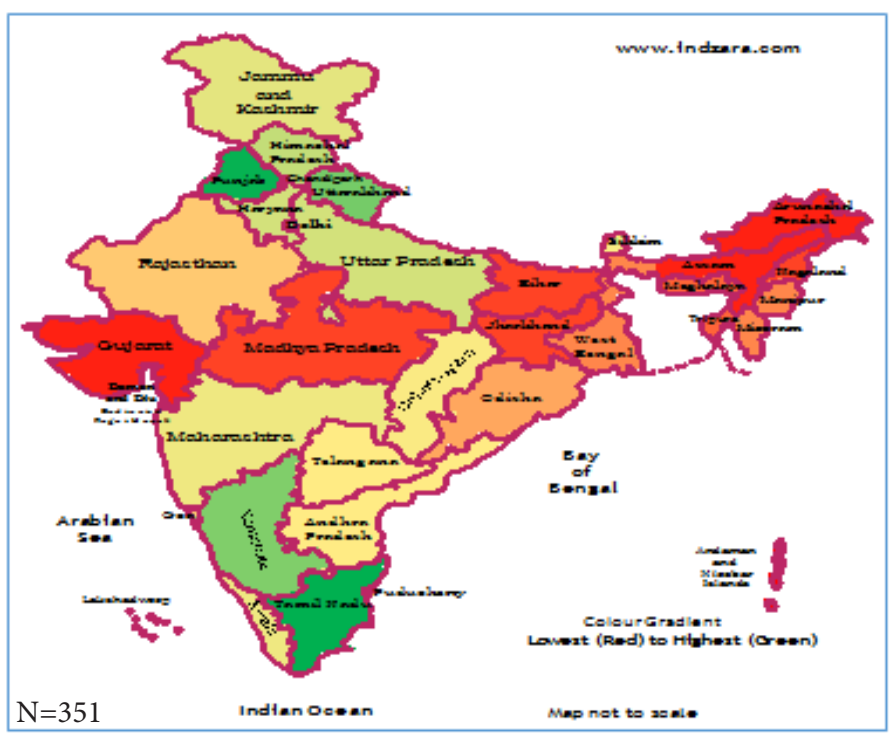

Distribution of responders across various states of India.

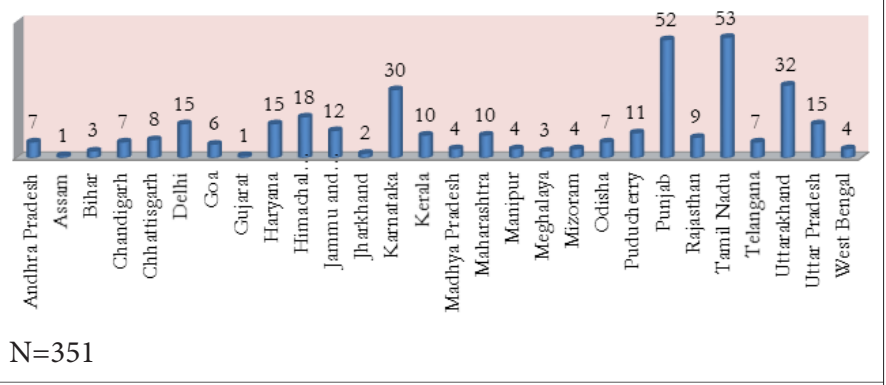

Figure 1: Distribution of responders across various states of India.
India and western countries also had similar characteristics. The study included participants from all the states of India. However, the majority of the respondents were from the States of Tamil Nadu and Punjab.

About $48 \%$ of Indian respondents of the present study reported that they were uncertain that the outbreak of coronavirus 2019 had created a worldwide health emergency, and $43 \%$ of the responders were unsure about whether the public follows social distancing seriously or not. It is a matter of concern that the general public still needs to have adequate awareness regarding COVID -19 .

However, most respondents $(76.9 \%)$ thought the social distance would prevent the spread of the virus. This may be due to more focus from the government and media on the preventive steps. Educated people and, in particular, people in health care get more sensitized by these facts.

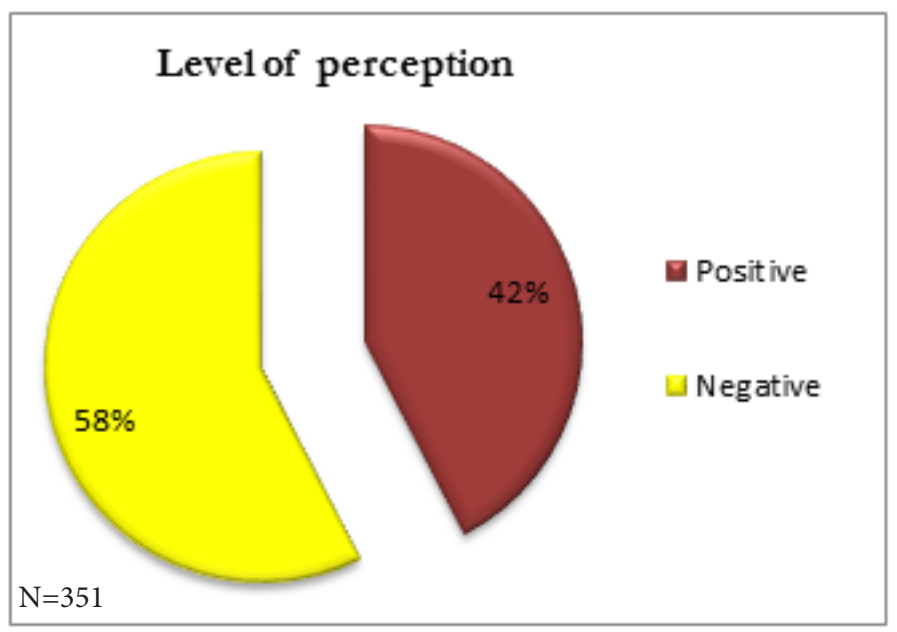

Figure 2: Level of perception regarding COVID 19.

Table 2: Item wise Perception of Indian population regarding COVID 19 pandemic.

\begin{tabular}{|c|c|c|c|c|c|c|}
\hline \multicolumn{7}{|l|}{$\mathrm{N}=351$} \\
\hline SI No & Items & $\begin{array}{c}\text { Strongly agree } \\
\mathrm{n}(\%)\end{array}$ & Agree $\mathrm{n}(\%)$ & $\begin{array}{l}\text { Uncertain } \\
n(\%)\end{array}$ & $\begin{array}{l}\text { Disagree } \\
n(\%)\end{array}$ & $\begin{array}{c}\text { Strongly Disagree } \\
n(\%)\end{array}$ \\
\hline \multicolumn{7}{|c|}{ I believe that } \\
\hline 1 & $\begin{array}{l}\text { The outbreak of coronavirus disease, } 2019 \text { (COVID-19), has } \\
\text { created a worldwide health emergency. }\end{array}$ & $169(48.1)$ & $46(13.1)$ & $48(13.8)$ & $33(9.4)$ & $55(15.6)$ \\
\hline 2 & $\begin{array}{c}\text { During this coronavirus period, lockdown for } 21 \text { days will } \\
\text { help spread the virus. }\end{array}$ & $172(49.1)$ & $49(13.9)$ & $55(15.7)$ & $38(10.8)$ & $37(10.5)$ \\
\hline 3 & $\begin{array}{c}\text { The economic down is a concern across India during this } \\
\text { period. }\end{array}$ & $125(35.6)$ & $64(18.3)$ & $87(24.8)$ & $44(12.5)$ & $31(08.8)$ \\
\hline 4 & Social distancing will prevent the coronavirus spread. & $270(76.9)$ & $54(15.4)$ & $18(05.1)$ & 05(01.4) & $04(01.2)$ \\
\hline 5 & $\begin{array}{l}\text { Residents of India are not following social distancing } \\
\text { seriously. }\end{array}$ & $76(21.7)$ & $61(17.4)$ & $151(43.0)$ & $39(11.1)$ & $24(06.8)$ \\
\hline 6 & $\begin{array}{l}\text { Effective health education/mass media communication } \\
\text { adopted in India is helpful in the prevention of COVID } 19 .\end{array}$ & $182(51.8)$ & $81(23.1)$ & $53(15.1)$ & $26(07.4)$ & $9(02.6)$ \\
\hline 7 & $\begin{array}{l}\text { Preparedness for COVID } 19 \text { of health care setting more } \\
\text { effective in our country. }\end{array}$ & $78(22.2)$ & $92(26.2)$ & $99(28.2)$ & $48(13.7)$ & $34(09.7)$ \\
\hline 8 & $\begin{array}{l}\text { Health care workers, police, and sanitary worker's } \\
\text { contribution to fighting against COVID } 19 \text { are well apparent. }\end{array}$ & $178(50.7)$ & $47(13.4)$ & $60(17.1)$ & $25(07.1)$ & $41(11.7)$ \\
\hline 9 & $\begin{array}{c}\text { It is the government's responsibility to fight against the } \\
\text { coronavirus. }\end{array}$ & $91(26.0)$ & $59(16.8)$ & $105(29.9)$ & $30(8.5)$ & $66(18.8)$ \\
\hline
\end{tabular}


Table 3: Level of anxiety about COVID 19.

\begin{tabular}{cccc}
$\mathrm{N}=351$ & & & \\
Level of anxiety & Score & $\mathrm{n}(\%)$ & Mean \pm SD \\
Mild & $0-6$ & $180(51.3)$ & \\
Moderate & $7-11$ & $101(28.8)$ & $5.66+4.829$ \\
Severe & $<11$ & $70(19.9)$ & \\
\hline
\end{tabular}

Median: 21, Range: 0-2

Table 4: Item-wise analysis anxiety of Indian population during COVID-19 pandemic.

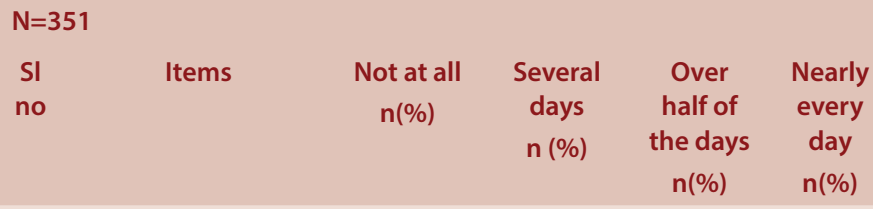

Over the last two weeks, how often have you been bothered by the following problems?

$\begin{array}{lccccc}1 & \begin{array}{c}\text { Feeling nervous, } \\ \text { anxious }\end{array} & 86(24.5) & 188(53.6) & 47(13.4) & 30(8.5) \\ 2 & \begin{array}{c}\text { Worrying too much } \\ \text { about different things }\end{array} & 178(50.7) & 107(30.5) & 47(13.4) & 19(5.4) \\ 3 & \begin{array}{c}\text { Not being able to stop } \\ \text { or control worrying }\end{array} & 95(27.1) & 159(45.3) & 55(15.6) & 42(12.0) \\ 4 & \text { Trouble relaxing } & 170(48.4) & 82(23.4) & 62(17.7) & 37(10.5) \\ 5 & \begin{array}{c}\text { Being so restless that } \\ \text { it's hard to sit still }\end{array} & 80(22.8) & 179(51.0) & 59(16.8) & 33(9.4) \\ 6 & \text { Becoming easily } & 176(50.1) & 88(25.1) & 56(16.0) & 31(8.8) \\ 7 & \begin{array}{c}\text { annoyed or irritable } \\ \text { Feeling afraid as if } \\ \text { something awful } \\ \text { might happen }\end{array} & 166(47.3) & 91(25.9) & 60(17.1) & 34(9.7)\end{array}$

Table 5: Co-relations between perception and anxiety among the general public.

$\begin{array}{ccccc}\mathrm{N}=351 & & & & \\ \text { Variables } & \text { Mean } & \text { SD } & r \text {-value } & p \text {-value } \\ \text { Perception } & 21.85 & 8.179 & 0.186 & 0.01^{*} \\ \text { Anxiety } & 5.66 & 4.829 & & \\ & & & & \end{array}$

${ }^{* *} p<0.001,{ }^{*} p<0.05$

Similar findings were reported by Roy et al. ${ }^{9}$ Parikh Priyanka A et al. ${ }^{10}$ reported that the general public was willing to follow the government protocol of quarantine and social distancing.

Recently, scholars have debated the adverse effects of the infectious outbreak (COVID-19) around the world. Academic Researchers are discussing the linkage between mental health issues and the COVID-19 epidemic more substantially. The current study finding reflected the public's fear and anxiety in which the majority of the Indian population reported moderate (29\%) and severe anxiety (20\%). This finding is consistent with a study from Germany Jungmann, Witthöft, ${ }^{11}$ from an Indian research Varshney et al. ${ }^{12}$ Wang et al. ${ }^{13}$ from China, and Salari, Hosseinian-Far, Alali, et al. (2020) in their meta-analysis documented that the prevalence of anxiety is $31.9 \% .^{14}$
The present study also revealed that about $45 \%$ of the responders reported that they are not being able to stop or control worrying about the pandemic situation, and more than $50 \%$ of participants felt being so restless that it is hard to sit still. Since these results occurred in the country during the early COVID-19 outbreak period, high chances are they may have changed over time and should, therefore, interpreted accordingly. The anxiety level in the present study seems to be high since it had $45 \%$ of the health professionals as respondents. Studies have reported that about $41 \%$ of health care workers were more anxious about COVID-19. ${ }^{15}$

Furthermore, the findings demonstrated a significant negative relationship between perception and the general public's anxiety. The above result is in line with similar prior researches.

Though our study population was not infected with COVID -19 infection, there is increased fear and anxiety, suggesting the need for improved mental health care. It can be assumed that persons diagnosed with or suspected of being diagnosed with COVID-19 infection and the health professionals associated with COVID-19 positive patients are likely to have higher reported mental health needs. ${ }^{15}$

\section{Limitations}

The study is limited to the citizens who had smartphones, e-mail ids, and the ability to understand English. It represents the educated population of the country; hence it cannot be generalized to the entire community. The perception, anxiety among uneducated people, may be diverse from the findings of our study.

\section{CONCLUSION}

The general public of the Indian population appears to have a negative perception regarding this pandemic situation, and they find it to have a mild to moderate level of anxiety. There is a need to exaggerate the understanding and address the mental health need of people during this COVID-19 pandemic.

\section{ACKNOWLEDGEMENT}

The authors thank all the responders involved in this study for their cooperation and support.

\section{CONFLICT OF INTEREST}

The authors declare that there is no conflict of interest.

\section{ABBREVIATIONS}

COVID 19: The coronavirus disease of 2019; WHO: World Health Organization; MoHFW: Ministry of health and family welfare.

\section{REFERENCES}

1. Hadil, Fatemah B, Alotaibi R. An analytical study on the awareness and practice during COVID 19 Pandemic in Riyadh, Saudi Arabia. Journal of Infection and Public Health. 2020;13(10):1446-52. Retrieved from https://doi.org/10.1016/j. jiph.2020.06.015 on 13.06.2020.

2. Chan JFW, et al. A familial cluster of pneumonia associated with the 2019 novel coronavirus indicating person-to-person transmission: A study of a family cluster. Lancet. 2020;395(10223):514-23.

3. Santabárbara J, Lasheras I, Lipnicki DM, Bueno-Notivol J, Pérez-Moreno M López-Antón R, etal. Prevalence of anxiety in the COVID-19 pandemic: An updated meta-analysis of community-based studies. Prog Neuropsychopharmacol Biol Psychiatry. 2020;109:110207. doi: 10.1016/j.pnpbp.202 0.110207. Epub ahead of print. PMID: 33338558

4. Chen F, et al. Depression and anxiety among adolescents during COVID -19: A cross-sectional study. Brain Behav Immun. 2020. Retrieved from https://dx.doi. org/10.1016\%2Fj.bbi.2020.05.061 on 21.07.2020.

5. Santabárbara J, Bueno-Notivol J, Lipnicki DM, Olaya B, Pérez-Moreno M, Gracia-García $\mathrm{P}$, et al. Prevalence of anxiety in health care professionals during the COVID-19 pandemic: A rapid systematic review (on published articles in 
Medline) with meta-analysis. Prog Neuropsychopharmacol Biol Psychiatry. 2021;110244. doi: 10.1016/j.pnpbp.2021.110244. Epub ahead of print. PMID: 33453320 .

6. Spitzer RL, Williams JBW, Kroenke K. Generalized Anxiety Disorder 7-Item (GAD-7) Scale. Arch Intern Med. 2020. [cited 2020Apr2]. Available from: https:// www.crossroadscounselingcenters.com/pdf/Generalized \%20Anxiety\% 20 Disorder.pdf

7. Vadivu S, Annamuthu P. An Awareness and Perception of COVID-19 among General Public-A Cross-Sectional Analysis. Int J Mod Trends Sci Technol. 2020;06(4):49-53. Available from: http://www.ijmtst.com/vol6issue04.html

8. Al-Hanawi MK, Angawi K, Alshareef N, Qattan AMN, Helmy HZ, Abudawood $\mathrm{Y}$, et al. Knowledge, Attitude and Practice Toward COVID-19 Among the Public in the Kingdom of Saudi Arabia: A Cross-Sectional Study. Front Public Health. 2020:8:217. doi: 10.3389/fpubh.2020.00217. PMID: 32574300; PMCID: PMC7266869.

9. Roy D, Tripathy S, Kar SK, Sharma N, Verma SK, Kaushal V. Study of knowledge, attitude, anxiety and perceived mental healthcare need in the Indian population during COVID-19 pandemic. Asian J Psychiatr. 2020;51:102083.

10. Parikh PA, Shah BV, Phatak AG, et al. COVID-19 Pandemic: Knowledge and Perceptions of the Public and Healthcare Professionals. Cureus. 2020;12(5):e8144. DOI 10.7759/cureus.8144.
11. Jungmann SM, Witthöft M. Health anxiety, cyberchondria, and coping in the current COVID-19 pandemic: Which factors are related to coronavirus anxiety? J Anxiety Disord. 2020;73:102239.

12. Varshney M, Parel JT, Raizada N, Sarin SK. The initial psychological impact of COVID-19 and its correlates in Indian Community: An online (FEEL-COVID) survey. PLoS One. 2020;15(5):e0233874. [cited 2020 Jul 19] Available from: https://dx.plos.org/10.1371/journal.pone.0233874

13. Wang C, Pan R, Wan X, Tan Y, Xu L, Ho CS, et al. Immediate psychological responses and associated factors during the initial stage of the 2019 coronavirus disease (COVID-19) epidemic among the general population in China. Int J Environ Res Public Health. 2020;17(5):1729. [cited 2020 Jul 19] Available from:/ pmc/articles/PMC7084952/?report=abstract

14. Salari N, Hosseinian-Far A, Jalali R, Vaisi-Raygani A, Rasoulpoor S, Mohammadi $\mathrm{M}$, et al. Prevalence of stress, anxiety, depression among the general population during the COVID-19 pandemic: A systematic review and meta-analysis. Global Health. 2020;16(1):57. [cited 2020 Jul 19] Available from: http://www.ncbi.nlm. nih.gov/pubmed/32631403

15. Temsah MH, Al-Sohime F, Alamro N, Al-Eyadhy A, Al-Hasan K, Jamal A, et al. The psychological impact of COVID-19 pandemic on health care workers in MERS-CoV endemic country. J Infect Public Health. 2020;13(6):877-82.

Cite this article : Malarkodi S, Belsiyal XC, Deol R, Sankarapandian C. Perception and Anxiety of Indian Population during COVID-19 Pandemic: A Questionnaire-based Survey. Int J Med Public Health. 2021;11(2):90-5. 